\title{
Netflix and Engage? Implications for Streaming Television on Political Participation during the 2016 US Presidential Campaign
}

\author{
Jacob Groshek * and Sarah Krongard \\ Division of Emerging Media Studies, Boston University, Boston, MA 02215, USA; krongard@bu.edu \\ * Correspondence: jgroshek@bu.edu; Tel.: +1-617-353-6421
}

Academic Editor: Terri Towner

Received: 30 June 2016; Accepted: 11 October 2016; Published: 21 October 2016

\begin{abstract}
A large body of existing research has consistently demonstrated that the use of social networking sites (SNS) by citizens in elections is positively related to different forms of both offline and online participation. The opposite argument, however, is often advanced with regard to increased viewing broadcast or cable television, particularly entertainment programming. This study proceeds from this broad vantage point by examining survey-based indicators of active SNS use and conventional television viewing in the 2016 presidential primaries, as well as the frequency of streaming television viewing during the early stages of this campaign. Data for this study was drawn from a representative nationwide online panel, and findings observed here suggest that more personalized communication through the ongoing morphology of social networking sites and streaming both political and apolitical television content are significant factors in positively shaping both online and offline participation. Comparisons with other media including conventional television viewing are introduced, and theoretical implications from a media system dependency framework are discussed.
\end{abstract}

Keywords: social media; streaming television; binge watching; political participation

\section{Introduction}

As has been well documented, the contemporary media landscape is constantly evolving the modalities of human communication, particularly in the political arena. Yet while certain linkages from macro-level indicators, such as the prevalence and use of social networking sites (SNS) for political purposes have been connected to structural changes in citizen engagement and mobilization at the individual level, the field is nearly absent an overarching framework that takes into account the drastic rise in media personalization, access, and the corresponding dependency cultivated in "always-on" media environments. Indeed, when considered at both social and individual levels, the "number and centrality of information functions" ([1], p. 1163) that certain media-in this case social media and (streaming) television - serve in society have likely never been higher.

From the vantage point of media system dependency (MSD) theory as originally articulated by Ball-Rokeach and DeFleur [2], it is the confluence of the widespread availability of social media and its highly personalized, algorithmically-informed content delivery system that function to augment not only media dependency but also more pronounced effects from that use. In the instances of election campaigns when the need for orientation [3] and uncertainty is relatively high among prospective voters, it can be argued that the second condition in MSD theory of increased sociopolitical conflict and change is also approximated, thereby increasing the likelihood of media dependency and subsequent effects.

This study thus proceeds to further examine the use of social media for political purposes, including the more personalized and expressive activities in those spaces and the ways in which the 
increased agency, (algorithmic) filtering, and choice in media may manifest as empowerment and transfer to differing dimensions of political participation. It continues to then explore how streaming television may be situated as an emerging phase in the continuum of media personalization and that this relatively active and highly individualized form of television use might fundamentally reshape not only the medium but also the agency ascribed to its users and its uses in the political arena. Similarly, while sundry studies have examined the relationship between traditional broadcast television and civic engagement, there is no research to our knowledge that deliberately addresses political implications of digital streaming television.

Although streaming television offers a blend of technological affordances that align with certain features of traditional broadcast television social media, it is a clear departure from both media and thus demands unique attention. This is particularly true as the modes of television production, distribution, and consumption are rapidly being transformed though online streaming interfaces. Altogether, this study breaks entirely new ground in an area of research-the confluence of social media and streaming television in political participation-that has to date been completely unexplored in the literature. Given the dramatic shift of viewers away from traditional television viewing to a mix of streaming online providers, the contribution of the findings reported here make a crucial and much need entry point to the field.

\section{Social, Mobile, Personal, and Ubiquitous Media System Affordances in Review}

The dramatic, concurrent rise in mobile devices and social networking sites (SNS) has taken place and contributed to shaping an individualized media environment. As these phenomena have emerged, the increasingly personalized nature of social media and its logic of sharing and (automated) recommending has resulted in scholarly explorations of these media and their relation to political engagement. For example, Gil de Zúñiga, Jung, \& Valenzuela [4] identified positive relationships between the informational use of SNS and engaging in political or civic action, and Bode [5] highlighted the potential for SNS users to learn about politics through social media; although, of course, results were not perfectly uniform. Along these lines, in a meta-analysis of thirty-six studies examining the relationship between social media and civic engagement, Boulianne [6] found an overall positive relationship, but there was minimal impact on social media use on participating in political campaigns.

Additional research has examined political implications of micro-level emerging media habits and behaviors, such as live-tweeting or second screening. To "live-tweet" is to engage via Twitter while viewing a real-time televised event, using a shared hashtag to participate in a broader, synchronous conversation with other users. Live-tweeting and similar online activities simultaneous with viewing television that have been conceptualized more broadly as second screening [7] engage the interactive elements of online communication and SNS to transform the traditional television consumption process into a dynamic, participatory experience. Breaking from a paradigm that suggested a certain passivity in television consumption, Vaccari, Chadwick \& O'Loughlin ([8], p. 1041), identified this dual screen viewing as "relatively active, 'lean-forward' practices" and noted that commenting live on social media and "engaging with conversations via Twitter hashtags have the strongest and most consistent positive associations with political engagement."

Continuing, recent work has found that news users are often looking to fulfill similar information functions whether using online or offline media [9], but those users that are more reliant on online and social media sources for news and information have noticeably different "diets" [10]. This tendency towards increased specialization and fixation on certain topics and uses in social media begins to signal both the differentiation of social media uses but also the increasing personalization of that content [11]. The direct, targeted communication between political actors and citizens [12] has also been shown to connect with augmented personalization in social media content, and personal political expression on social media in particular has been linked to increased political participation [13].

Thus, the affordances of emerging participatory technologies cultivate a personalized media ecosystem that empowers users with persistent perceived agency and control. Media are constant, 
ubiquitous, and tailored to the individual; users of SNS have the power to craft and curate their mediated experiences. Such functionality is now expected for emerging media technologies; yet despite the increase in options, conventional television viewing is still the most dominant form of media consumed [14]. That said, as demonstrated through viewing behaviors such as live-tweeting and other forms of second (or multi) screening, television is now only part of the larger media dialogue, where traditional and emerging tools interface with one another; users now require and demand interactive communication, opportunities for sharing, and increased control.

In alignment with MSD, this fluid technological environment cultivates increased dependency on new media affordances due to the increasingly individualized and thereby personally relevant content. Hence, it is necessary to examine the role of personalized communication in the contemporary media landscape, specifically as social media use and its logic of individualization intersects directly with media exposure outcomes, specifically in the area of streaming television. Most notably, social media and its logic for more personalized communication, particularly in the political realm, is crucial in that it contributes to making recommendations, opens a platform for sharing, and allows for communicating around media content-and that shift is now writ large as television is renegotiated to a streaming rather than broadcast modality.

\section{Social Media, Personal TV}

Technologically, the term "television" no longer refers to a stationary, glowing box situated in the living room, a conceptualization that emerged from the network-era of programming [15]. Today, "television" is mobile, connected, and ubiquitous, permeating all internet-enabled devices, which again signals a vastly increased dependency norm. Here, rather than simply a machine or vehicle, television functions as a "technology and a tool for cultural storytelling" as well as "the set of behaviors and practices associated with its use" ([15], p. 29). While the process of storytelling is technologically agnostic, each communication vehicle offers specific affordances that encourage certain behaviors and interactions [16].

From an historic perspective, the "golden age of television" in the United States was led by the "big three" networks, ABC, NBC, and CBS [17]. Viewers consumed a limited number of television programs and experienced the content synchronously, creating a shared, linear cultural experience. TV evolved through the "multi-channel transition" (mid-1980s through the mid-2000s) when the advent of cable offered audiences increased choice and control over content consumed [15]. Within the public discourse, however, cable did not achieve its promise. According to Streeter (1997), "Cable was to be interactive; instead it is just as one-way as its predecessors. Cable was to end television oligopoly; instead it has merely provided an arena for the formation of a new oligopoly. Cable was to cure social ills; instead it at best distracts from those ills" ([18], p. 240). Cable television, and arguably commercial broadcast television networks thus serve as examples of misalignment between the affordances of communicative technology and its social application to democratic ideals.

The relationship between traditional television and political engagement has been explored extensively during the network and cable eras of television and a series of inquiries have offered mixed results. With regard to overtly political television content, such as news and televised political discussion or debates, Drew and Weaver [19-23] found that the relationship between political understandings and television is specific to the context of the campaigns. Drew \& Weaver examined television's role in learning about the political climate, such as understanding party and campaign issues as well as campaign interest, during the presidential elections from 1988 through 2004 elections. In 1992 and 2000, viewing the televised debates served as the strongest predictor campaign interest $[20,22]$ and the "general lack of interest" in the 1996 election may have been the reason for a notably diminished impact of media coverage on engagement during that specific campaign year. In 2004, traditional media, including television, served as the strongest predictor of interest in the campaign, with the internet emerging as an increasingly important variable [23]. These findings 
suggest the importance of both the political and technological contexts in shaping audiences interest, knowledge, and intention to vote in elections [24,25].

Importantly, viewing televised political satire, such as The Daily Show and The Late Show, has also demonstrated significant positive effects on political engagement [26,27]. Here, additional studies have examined politically agnostic television content consumption and its relationship to political engagement among viewers, particularly as opposed to newspaper readership. McLeod, Glynn, and McDonald [28] found that generally television-reliant voters focus more on image-based characteristics, as opposed to newspaper-reliant voters. According to Putnam's "bowling alone" argument $[29,30]$, traditional television consumption was to positioned as a key factor that contributed to a precipitous decline in social capital and civic engagement. Still, later [31,32] refuted Putnam's assertions, and Shah [33] found that the content consumed, rather than just time spent with the medium was a pivotal factor in the dynamic between media use and individual-level political engagement.

Along these lines, Mutz and Nir [34] found that fictional dramas can influence viewers' political views and policy decisions, noting that the viewers' emotional involvement in the content might explain the impact. Specifically, they suggest that because empathy creates a strong connection to televised content, fictional dramas might prove more powerful than explicitly political content like televised news due to the narrative transportation. In a qualitative study exploring the civic attitudes of young people, Street, Inthorn, and Scott [35] found that popular culture served as an indirect source of political information and ideas.

Therefore, this study addresses a gap in the body of research on television and political engagement, specifically examining the contemporary affordances of digital streaming television and its political implications. Today's "post-network" era offers a similar promise of enhanced choice, freedom, and personalization. Broadcast television remains the dominant form of media consumed, but viewing behaviors have shifted to a growing trend away from traditional cable packages and toward online streaming subscriptions through providers such as Netflix, Hulu, and Amazon Prime [36]. Recently, Netflix reported more than 75 million subscribers in over 190 countries [37] cumulatively streaming more than 42.5 billion hours of content in 2015 [38], and as of early 2015, Hulu reported nine million subscribers [39]. Demonstrating this trend further, according to its annual report Amazon Prime membership grew by 14 million members in 2015 to reach 54 million members in the US alone, though not all may be utilizing their membership to stream television, which is just one of several features [40]. In addition, Nielsen [41] reported that these subscription video on-demand services are now found in $50 \%$ of U.S. households, which is roughly equivalent to the presence of digital video recorders (DVR).

In this shifting landscape, Alvarez-Monzoncillo [42] refers to these "aggregators" like Netflix and Amazon Prime as "virtual shops...[t]hey are new intermediaries who sell programmes that others lend them to be marketed. The models they use are broad and varied, ranging from a video-on-demand style ...to hybrid systems between the physical and virtual worlds for video rentals" (Kindle Location 272). These aggregators currently inhabit a space within the contemporary e-commerce environment, contributing to the reshaping of media consumption once dominated by the big three and cable networks.

In many ways, and for millions of users, the act of television viewing is now personal, unique, and individually determined due to time-shifting technologies, such as DVR, Roku, Chromecast, Apple TV, and other online streaming television services that likewise interface directly with social media in terms of recommendations and sharing functions. Alvarez-Monzoncillo [42] explores this contemporary relationship between audience and television consumption, stating that "the flexibility of Internet platforms and devices entails a new dictatorship of the audience making it possible for the content to be broadcast ubiquitously over multiple distribution platforms" (Kindle Location 31). Alvarez-Monzoncillo's use of the term "dictatorship" suggests unconditional, unidirectional power currently in the hands of the audience. He continues by stating, "TV consumers have acquired a taste for the on-demand culture. In conjunction with the 'always on' trend, this has broken down 
the old logic of the multichannel television, leading to new content that enables an immediate and virtually à la carte experience. We now have multiplatform formats that match new lifestyles and social relationships" (Kindle Location 210).

With increased individualization of the mediated experience comes a shift in conceptualizations of audience, and to this extent the BBC has been reported to be considering dropping its channel-based structure [43]. Similarly, Lotz ([15], p. 5) maintains that "the U.S. television audience now can rarely be categorized as a mass audience; instead, it is more accurately understood as a collection of niche audiences." This collection of niche audiences is inherently connected to media fragmentation. According to Napoli ([44], p. 57) as "media technologies continue to facilitate the increasing fragmentation of content options, the distribution of audience attention to a certain degree follows suit."

This highly personalized media environment provides users with increased choice, control, and opportunity for exploration of new content. In order to facilitate the process of choice, online televisions streaming platforms employ algorithmic recommendation systems using data gathered about the user. These data then inform the technology's understanding of the user's needs and preferences. Television applications such as Netflix and Hulu employ recommendation algorithms that are similarly used very explicitly through matchmaking applications such as match.com and music platforms such as Pandora or Spotify, or more subtly via Facebook friend recommendations or Google advertisement placements within searches or the Gmail inbox interface. Of course, though, the "inner workings" of recommendation systems are often "wired shut with patent and trade secret laws, non-disclosure agreements, non-compete clauses, and other legal instruments" ([45], p. 117).

Services like Netflix and Hulu incorporate algorithms, a process that "ultimately exercises control over us by harnessing these forces through the creation of relationships between real-world surveillance data and machines capable of making statistically relevant inferences about what that data can mean" ([46], p. 178). Although today's television climate provides viewers with a more personalized experience, creating a sense of choice and freedom users are constantly being conditioned by those very same recommendation systems, which thereby focus the range of choices and limit potential content diversity.

Therefore, digital television integrates social media logic [47], adopting the qualities and elements that facilitate these technological interactions. From the perspective of Media System Dependency (MSD) theory as shown in Figure 1, the dramatic increase in and emphasis on communication technologies that empower control, agency, and personalization among users may foster an increased cognitive expectation for these affordances when they are prevalent in an immersive and always-on-demand media landscape. Along these lines, several decades ago, Miller and Reese ([48], p. 1) found that the "reliance on a medium enhances positive associations between exposure to that medium and political efficacy and activity." McLeod and McDonald ([49], p. 2) followed their study, finding to "again confirm an integrative role for television" in the political process while suggesting content and not just exposure were crucial in determining political effects that could be observed related to television viewing.

Altogether, research in the field has detailed at great lengths the role of social media in politics, as well as the role of traditional broadcast television in political engagement, but very little formal research exists on streaming television, and none- to the best of our knowledge-has examined how the shift to streaming television is related to political participation. Due to the original nature of this piece, it is necessary to initially address the users of streaming television to fully understand the context of the study. Therefore, we begin by advancing the following research question:

RQ1: How many users stream television-and which characteristics are related to more frequent television streaming?

Continuing, based on the preceding review of literature on social media and political participation, this study therefore advances the following hypothesis: 
H1: Greater frequency of streaming television online (via computer, internet-enabled television, or mobile device) will also relate positively to higher levels of (a) online and (b) offline political participation.

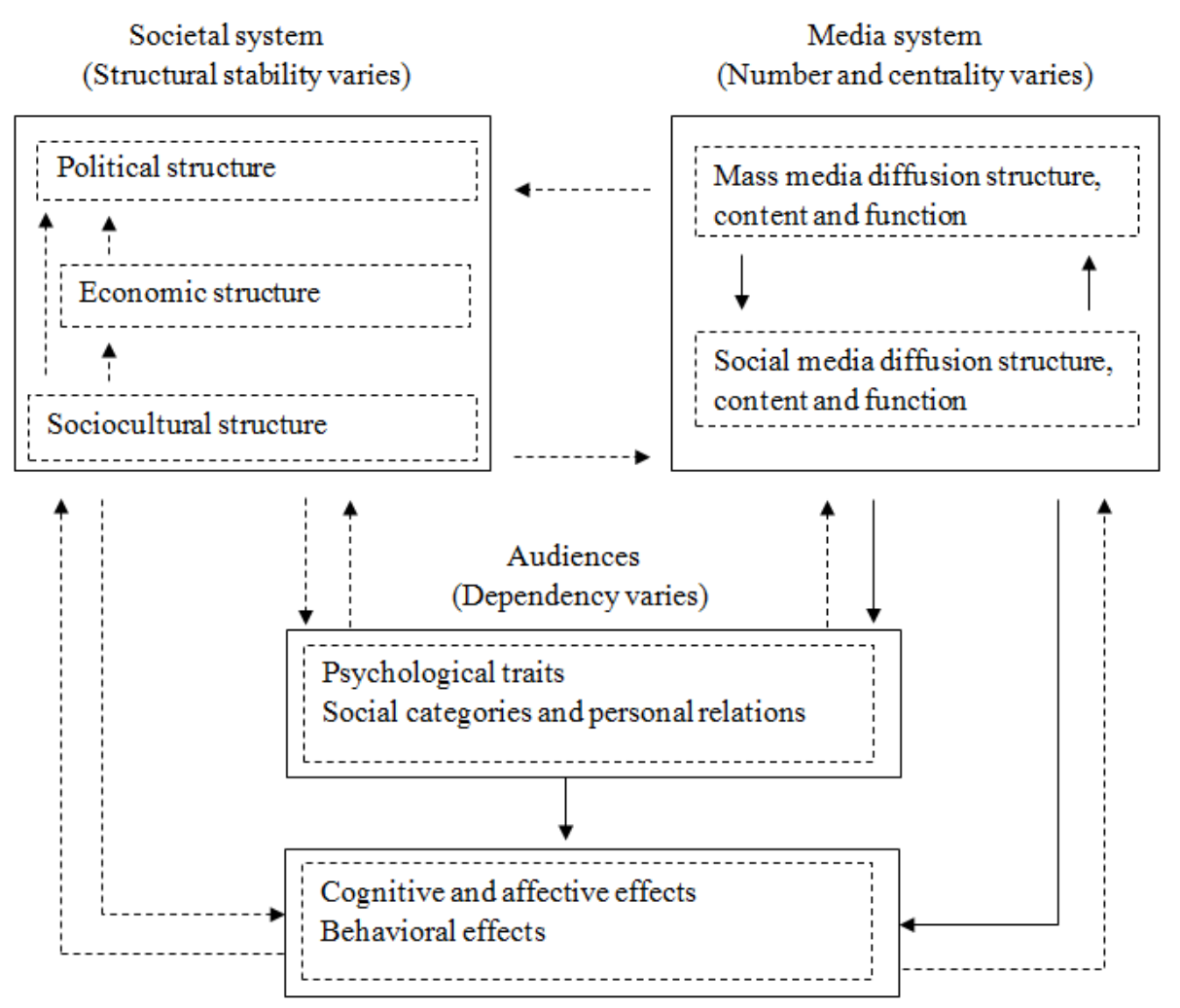

Figure 1. Proposed media system dependency personalization and political participation framework [2,50]. Notes: Solid arrows indicate relationships examined in this study; dashed arrows indicate mechanisms that contextualize proposed linkages, but were not directly measured.

Moreover, given the emergent state of research in the area, this study further investigates the type of content-political or apolitical-that users report binge watching through streaming television. While Graham and Hajru [51] found that even apolitical television content such as reality TV can stimulate political participation online, there is a general tendency in the literature towards political content. In addition, as mentioned above, entertainment-oriented programs like The Daily Show and late night talk shows [27,52] have been previously been shown to connect to political interest and participation. We thus pose the following research question to investigate the role of content in streaming television and its linkage to politics to explore if there is a difference related to content type rather than platform alone:

$R Q 2$ : To what extent does viewing political or apolitical content interact with the frequency of streaming television online and relative levels of a) online and b) offline political participation?

\section{Methods}

Data for this study was collected over the period of November 16 through 3 December 2015 and comprised 1105 respondents from an opt-in online panel coordinated through the survey company Qualtrics. Specifically, there were 516 male respondents (46.7\%) and 589 female respondents $(53.3 \%)$, with a median age of 44 years (mean $=45.19, \mathrm{SD}=17.14$ ). In terms of income, $26.2 \%$ earned $\$ 24,999$ or less, $27.1 \%$ made between $\$ 25,000$ and $\$ 49,999$ as a household, $30.3 \%$ were in the $\$ 50,000$ to $\$ 99,999$ income bracket, and $16.4 \%$ reported earning $\$ 100,000$ or more annually. These breakdowns, as with those of ethnicity, namely $74.1 \%$ respondents indicating being Caucasian, $11.0 \%$ and $7.2 \%$ 
identifying as African American and Hispanic/Latino, respectively, with another 5.2\% indicating being Asian, $1.3 \%$ Native American, $0.3 \%$ Pacific Islander, and $0.9 \%$ self-identifying as 'other' ethnically are consistent with figures from the general US population, as are education figures.

This sample is highly comparable along demographic lines to the broader US population, but there are some limitations to perfect generalization as a result of opt-in online panel sampling [53,54]. Still, it is vital to identify that such stratified online quota samples are contemporarily being used similarly in the discipline and regularly apply inferential statistics [6].

\subsection{Political Antecedents}

Like nearly all studies of political communication, this study took into account self-reported political party affiliation as well as political ideology. In this sample, $27.7 \%$ of respondents indicated being Republicans and $35.4 \%$ were self-identified Democrats, which left a remaining $33.1 \%$ as Independents, $2.3 \%$ as 'other', and $4.5 \%$ that 'don't know' their party affiliation. Political ideology was set on a one (very liberal) to seven (very conservative) scale, which had a mean of $3.98(\mathrm{SD}=1.83$ ). Political knowledge was determined by respondents answering four general political knowledge questions, such as the number of Supreme Court justices and identifying Angela Merkel's position. On this scale, $7.7 \%$ of respondents answered no questions correctly, $17.6 \%$ and $21.7 \%$ answered one and two questions accurately, there were $24.4 \%$ of respondents answered three questions properly and $28.9 \%$ choose correct responses to all questions posed $(\mathrm{M}=2.49, \mathrm{SD}=1.28)$.

\subsection{Political Efficacy and Voting Behavior}

Political efficacy was collected on both internal and external metrics, following questions common to the discipline. The internal efficacy scale was based on three items (Cronbach's alpha $[\alpha]=0.781$ ) and had an ordinal range of one (very low) to five (very high) and a mean of $3.27(\mathrm{SD}=0.94)$. The external efficacy measure $(\mathrm{M}=3.39, \mathrm{SD}=1.13)$ was based on two questions $(\alpha=0.769)$ and followed the same five point scale. Frequency of voting in local and state elections similarly comprised two items $(\alpha=0.948)$, and was calculated on a zero (never) to four (always) ordinal level, with a mean of 2.20 $(\mathrm{SD}=(1.61))$.

\subsection{Frequency of Talking Politics}

Two scales of talking politics, one for face-to-face and the other for online, were identified through, like other scales reported, a factor analysis process with varimax rotation. Both scales were based on responses to eight items that measured the frequency (never [0]-always [4]) of talking politics to a variety of other individuals, from people like family and friends, strangers, and those with differing opinion. For the face-to-face index $(\alpha=0.949)$, the average was $1.16(\mathrm{SD}=0.94)$ and the online talking politics measure $(\alpha=0.968)$ had a mean of $0.94(S D=1.02)$. Not surprisingly, these variables correlated strongly with one another (Pearson's $r=0.82, p<0.01$ ), suggesting that respondents that generally talk politics frequently often do so both online and offline.

\subsection{General Use of Media for Politics}

A series of statements assessed how regularly participants used different forms of media to gather information about politics and elections. These were centered around certain technological interfaces, and included three general news use and information scales gathered on the same ordinal zero (never) to four (always) level of measurement. Of these media use scales, respondents reported how often they watch local, network, and cable news (three items; $\alpha=0.747$ ) through conventional television viewing, which had a mean of $2.38(\mathrm{SD}=0.97)$. Survey participants also indicated the time $(\mathrm{M}=1.21$, $\mathrm{SD}=0.91)$ they spent consuming radio news and talk radio, as well as national and local newspapers in print (four items; $\alpha=0.725$ ). 


\subsection{Social Media and Streaming Television}

The independent variables of most interest to this study likewise had a range from 'never' (0) to 'always' (4), and also comprised multiple items each. One constructed variable in this block estimated using social network sites for political purposes and included the frequency respondents indicated doing each of the follow seven activities: posting personal experiences related to politics or campaigning, friending or following a political actor, receiving messages from parties or politicians, posting or sharing (a) thoughts or (b) media such as photos, videos or audio content about current events or politics, forwarding someone else's political commentary, and arguing with someone on SNSs that has different political views $(\alpha=0.933)$. Once compiled, this variable averaged $0.84(S D=0.93)$ for this sample.

The other variable in this personalized media block had to do with frequency of streaming television on laptops, desktops, internet-enabled television, mobile phones, or tablets. This metric also ranged from zero to four, but unlike the other constructed variables, on this scale (five items; $\alpha=0.870$ ), zero refers to no streaming television use at all, one represents some, but less than one hour of streaming television on a typical day, and two references between one and two hours, three is equivalent to from two and three hours, and four equals three hours or more of online television streaming across all devices in a normal day. Along this scale, the average level of streaming personalized television was $1.28(\mathrm{SD}=1.23)$ among this sample.

In terms of content, all respondents were asked to identify not only if they had binge watched programs through streaming television platforms but also which programs those were. In order to differentiate political from apolitical content, we sampled six of the most frequently streamed shows among our respondents. Three of these-House of Cards, Orange Is the New Black, and Homeland-could be considered political in nature. The other three-The Unbreakable Kimmy Schmidt, The Walking Dead, and Game of Thrones — can fairly be estimated as largely apolitical programs. Viewers of political (12.7\%; $\mathrm{N}=140)$, apolitical $(17.8 \% ; \mathrm{N}=197)$, and both $(15.2 \% ; \mathrm{N}=168)$ types of content were combined into one variable for comparative purposes. There were 600 respondents $(54.3 \%)$ that indicated not streaming either political or apolitical programming, or not streaming television at all.

\subsection{Political Participation}

The two key dependent variables in this study were online political participation $(\alpha=0.917)$ and offline political participation $(\alpha=0.878)$, and both were based closely on a series seven items that have been validated in prior research [13]. In terms of online political participation $(\mathrm{M}=0.48 ; \mathrm{SD}=0.77)$, respondents were asked to gauge how often in the past twelve months on 'never' (zero) to 'always' (four) scales that they had used the internet perform activities such as making a campaign contribution, signing up to volunteer for a campaign or issue, subscribing to a political listserv, writing a letter to the editor (online), creating posts for a blog, or participating in online activities organized by a political movement. Offline political participation $(\mathrm{M}=0.71$; $\mathrm{SD}=0.81)$ applied nearly identical items on the same scale but had those activities, such as writing a news organization, taking place without using the internet. Additional offline items included actions that are not (easily) recreated or do not exist online, such as attending public hearings, town hall meetings, political rallies or other interactions that specifically require a physical presence such as protesting or marching.

Here it is useful to note that the conceptual and correlational overlap with social media use for political participation was evident but not overwhelming $(r=0.70, p<0.001)$ for online and $(r=0.654$, $p<0.001)$ offline activities, and that these measures have been validated through previous research.

\section{Findings}

This study began by examining RQ1, as well as how prevalent streaming television was in this sample and which characteristics helped to explain which users were active in streaming television more frequently across screens. Here, 27.9\% (308) respondents indicated having never streamed 
television at all, and another $43.5 \%$ reported an hour or less in a typical 24-hour period across all devices. Another $12.7 \%$ and $4.9 \%$ watched between 1-2 and 2-3 hours of streaming television, and $11 \%$ had their eyes on streaming television 3 or more hours per day. The distribution of the variable was within normal skewness parameters (1.04), and while it suggests that streaming television was not especially heavy in this sample, it was a media activity that $72.1 \%$ of respondents did at least some of the time in a normal day.

Continuing, a bivariate correlation matrix of all variables considered here provides some relevant indicators to not only illuminate those who stream television more regularly but also set a baseline for the remainder of hypotheses and research questions put forth in this study. Here, it can be observed that younger individuals (Pearson's $r=-0.300, p<0.001$ ) streamed television more frequently, as did those that watched more traditional television $(r=0.148, p<0.001)$, listened to the radio more often $(r=0.348$, $p<0.001)$, and that relied on SNSs for political purposes, which had the strongest correlation $(r=0.443$, $p<0.001)$, which still was only a moderately strong relationship. Other significant relationship showed that more liberal respondents streamed television more $(r=-0.167, p<0.001)$, as did those that were less politically knowledgeable $(r=-0.177, p<0.001)$ and had lower external political efficacy levels $(r=-0.073, p<0.05)$.

Generally speaking, there were also positive relationships between the frequency of talking politics face-to-face $(r=0.378, p<0.001)$ and online $(r=0.414, p<0.001)$, and there was preliminary evidence that those more active in participating in politics in online and offline were also streaming television more regularly $(r=0.400, p<0.001$ and $r=0.396, p<0.001$, respectively). While such correlational relationships are not definitive, this overview gives a general sense of which users were streaming television more often-and somewhat interestingly there were no significant relationships observed with gender, education, or income levels. Table 1 summarizes the remainder of correlations for the key variables of interest in this study and provide and framework for the remaining analyses.

Table 1. Pairwise correlations for frequency of streaming television, using social network sites for political purposes as well as online and offline political participation.

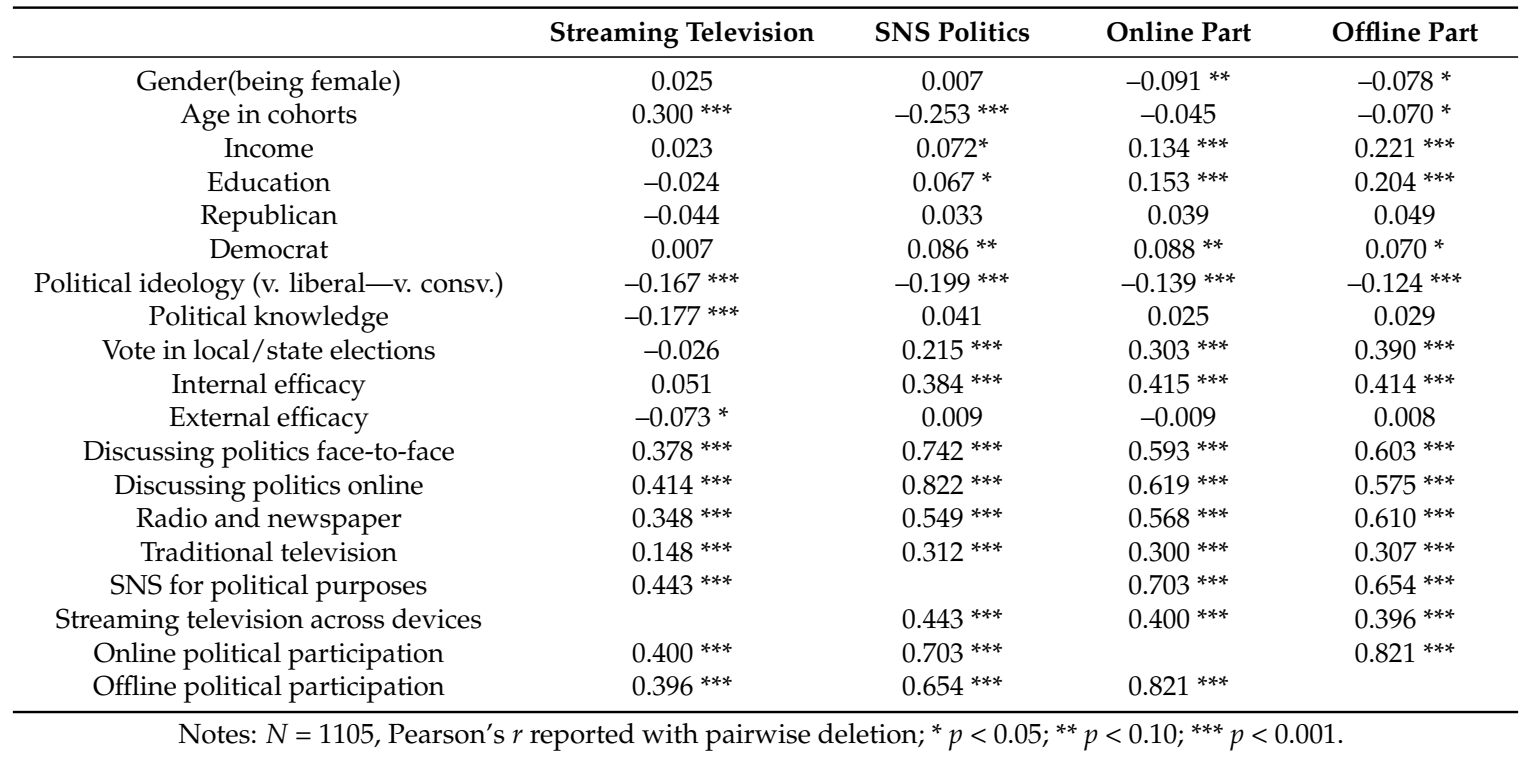

Switching now to analyze Hypotheses 1 and whether greater frequency of streaming television online (via computer, internet-enable television, or mobile device) will also relate positively to higher levels of (a) online and (b) offline participation, this study again begins by looking at basic crosstabulations. In these tests, the streaming television variable was maintained on its none, less than 
one, one-two, two-three, to three(or more) hourly scale, as its collection and computation lends it such an analysis because its values exist as whole numbers.

When looking at online political participation as a binary proposition-respondents indicating having "none" or "some"-it was clear that more hours spent streaming television was related to generally increasing percentages of those that participated in politics to those that did not $\left(\chi^{2}(\mathrm{df}: 4)=40.64, p<0.001\right.$; Kendall's tau-c $\left.\left[\tau_{\mathrm{c}}\right]=0.18, p<0.001\right)$. The lowest percentage of political participation (44.2\%) online was observed among the 308 respondents that reported never streaming television or doing so one hour or less in a given day, and that figure increased to $50.1 \%, 55.7 \%$, and $79.6 \%$ among those streaming less than 1 hour, 1-2 hours, and 2-3 hours, respectively, before dipping to $69.7 \%$ among those streaming 3 or more hours of television per day. Offline political participation generally followed this pattern, and was also statistically significant $\left(\chi^{2}(\mathrm{df}: 4)=19.74\right.$, $\left.p<0.05 ; \tau_{c}=0.12, p<0.001\right)$ across increasing levels of streaming television, from $65.6 \%$ to $73.2 \%$ among those viewing none and $0-1$ hours. Levels in offline political participation continued to $71.4 \%$ and $81.5 \%$ for those spending 1-2 and 2-3 hours streaming TV before climbing to $85.2 \%$ among those streaming $3+$ hours daily.

Altogether, at the level of simple frequencies there is support for $\mathrm{H} 1 \mathrm{a}$ and $\mathrm{H} 1 \mathrm{~b}$, and this study therefore proceeds to examine average levels of online and offline political participation as these vary across viewership lefts. Put briefly, the results showed uniformly upward trends and statistically significant results for online $(F(4,233.59)=25.15, p<0.001$, equal variances not assumed $)$ and offline $(F(4,236.49)=27.74, p<0.001$, equal variances not assumed $)$ political participation. Average political activities online increased sequentially for every increase in streaming television time, from a low of $0.26(\mathrm{SD}=0.46)$ among those that spent no time streaming to a high of $1.25(\mathrm{SD}=1.4240)$ for those reporting three or more hours. Nearly identical increases in the average levels of participating in politics offline, from a mean of just $0.47(\mathrm{SD}=0.55)$ in the nonstreaming cohort, which steadily increased at each streaming level until peaking at average of $1.51(\mathrm{SD}=1.24)$ for those that streamed television for three hours or more.

At this point, analyses continued with hierarchical regression models for online and offline political participation that took into account a range of germane independent variables to better explicate the effect of personalized communication on social network sites. Based on previous research [12], it is again unsurprising to find that online and offline political participation were highly correlated with one another (Pearson's $r=0.82, p<0.001$ ) and as such were excluded from regression modeling to avoid issues of multicollinearity.

In the first model, the dependent variable of online political participation was related to a number of key factors (for a complete summary see Table 2; additional discussion to follow), specifically including the more regular use of SNS for personalized political information $(B=0.41, p<0.001)$. In this analysis, each unit increase in the political use of SNSs was related to a substantial 0.41 unit increase in online political participation. Moreover, when comparing standardized Betas in the model, increased use of social networking sites was the strongest statistically significant predictor $(\beta=0.49)$.

The next model situated offline political participation as the dependent variable and likewise found increased use of SNS for political purposes was positively and significantly $(B=0.33, p<0.001)$ related to that outcome. While in this model (see Table 3 ) there were slightly more statistically significant predictors and the relative effect of SNS use was somewhat less $(\beta=0.38)$, it also was the largest standardized Beta in this model, and these findings nonetheless roundly support both Hypotheses $1 \mathrm{a}$ and $1 \mathrm{~b}$. 
Table 2. Regression Model of Online Political Participation.

\begin{tabular}{|c|c|c|c|}
\hline & Coefficient (B) & Standard Error & $\operatorname{Beta}(\beta)$ \\
\hline \multicolumn{4}{|c|}{ Step 1-Demographics } \\
\hline Gender (being female) & $-0.062^{\#}$ & 0.035 & -0.039 \\
\hline Age in cohorts & $0.098^{* * *}$ & 0.020 & 0.115 \\
\hline Income & -0.002 & 0.018 & -0.003 \\
\hline Education & 0.020 & 0.013 & 0.035 \\
\hline$\Delta R^{2}$ & $0.031 * * *$ & & \\
\hline \multicolumn{4}{|c|}{ Step 2-Political Antecedents } \\
\hline Republican & 0.006 & 0.044 & 0.003 \\
\hline Democrat & 0.030 & 0.041 & 0.018 \\
\hline Political ideology (v. liberal—v. conservative) & -0.010 & 0.011 & -0.024 \\
\hline Political knowledge & $-0.037^{* *}$ & 0.014 & -0.059 \\
\hline$\Delta R^{2}$ & $0.034^{* * *}$ & & \\
\hline \multicolumn{4}{|c|}{ Step 3-Political Efficacy and Voting Behavior } \\
\hline Vote in local/state elections & $0.035 * *$ & 0.012 & 0.071 \\
\hline Internal efficacy & $0.109^{* * *}$ & 0.022 & 0.124 \\
\hline External efficacy & $-0.045^{* *}$ & 0.015 & -0.063 \\
\hline$\Delta R^{2}$ & $0.184^{* * *}$ & & \\
\hline \multicolumn{4}{|c|}{ Step 4-Frequency of Talking Politics } \\
\hline Discussing politics face-to-face & 0.0034 & 0.032 & 0.040 \\
\hline Discussing politics online & 0.015 & 0.033 & 0.019 \\
\hline$\Delta R^{2}$ & $0.216^{* * *}$ & & \\
\hline \multicolumn{4}{|c|}{ Step 5-General Use of Media for Politics } \\
\hline Radio and newspaper & $0.150 * * *$ & 0.025 & 0.173 \\
\hline Traditional television & $-0.042 *$ & 0.020 & -0.051 \\
\hline$\Delta R^{2}$ & $0.045^{* * *}$ & & \\
\hline \multicolumn{4}{|c|}{ Step 6-Social Media and Streaming TV } \\
\hline SNS political purposes & $0.410^{* * *}$ & 0.033 & 0.491 \\
\hline Streaming television across devices & $0.075^{* * *}$ & 0.016 & 0.117 \\
\hline$\Delta R^{2}$ & $0.079^{* * *}$ & & \\
\hline
\end{tabular}

Notes: $N=1024$, listwise deletion; overall Adjusted $R^{2}=0.582$; ${ }^{\#} p<0.10 ;{ }^{*} p<0.05 ;{ }^{* *} p<0.10 ;{ }^{* * *} p<0.001$.

With these models in place, and the relative import of SNS use already reported, this study progressed to further explore this pair of hierarchical regression models to more fully examine the role of streaming television as it related to online and offline political participation. Returning to the first of those models (summarized in Table 2), which took into account a wide range of control variables, the increased frequency of streaming television was a statistically significant predictor of online political participation $(B=0.08, p<0.001)$, though its relative effect in the overall model was quite modest $(\beta=0.12)$. Similar, positive and significant findings were likewise observed in the second model (summarized in Table 3) when examining the relationship between streaming television and offline political participation. In this case, each additional hour of streaming was related to a 0.08 increase in engaging offline political activities $(p<0.001)$. While this overall relationship is thus somewhat limited, it is in line with other independent variables and its contribution in terms of standardized Betas $(\beta=0.13)$ is only slightly less than discussing politics face-to-face $(\beta=0.15)$ and nearly double that of internal efficacy ( $\beta=0.07$; see Tables 2 and 3 for full model summaries). 
Table 3. Regression Model of Offline Political Participation.

\begin{tabular}{|c|c|c|c|}
\hline & Coefficient (B) & Standard Error & $\operatorname{Beta}(\beta)$ \\
\hline \multicolumn{4}{|c|}{ Step 1-Demographics } \\
\hline Gender (being female) & 0.005 & 0.036 & 0.003 \\
\hline Age in cohorts & $0.043 *$ & 0.021 & 0.048 \\
\hline Income & $0.050 * *$ & 0.018 & 0.063 \\
\hline Education & $0.033 *$ & 0.014 & 0.055 \\
\hline$\Delta R^{2}$ & $0.067^{* * *}$ & & \\
\hline \multicolumn{4}{|c|}{ Step 2-Political Antecedents } \\
\hline Republican & -0.039 & 0.046 & -0.021 \\
\hline Democrat & -0.038 & 0.043 & -0.022 \\
\hline Political ideology (v. liberal—v. conservative) & -0.015 & 0.011 & -0.034 \\
\hline Political knowledge & $-0.054^{* * *}$ & 0.014 & -0.083 \\
\hline$\Delta R^{2}$ & $0.028^{* * *}$ & & \\
\hline \multicolumn{4}{|c|}{ Step 3-Political Efficacy and Voting Behavior } \\
\hline Vote in local/state elections & $0.096^{* * *}$ & 0.013 & 0.186 \\
\hline Internal efficacy & $0.068^{* *}$ & 0.023 & 0.074 \\
\hline External efficacy & -0.034 * & 0.016 & -0.046 \\
\hline$\Delta R^{2}$ & $0.205^{* * *}$ & & \\
\hline \multicolumn{4}{|c|}{ Step 4-Frequency of Talking Politics } \\
\hline Discussing politics face-to-face & $0.130 * * *$ & 0.033 & 0.148 \\
\hline Discussing politics online & $-0.071 *$ & 0.035 & -0.088 \\
\hline$\Delta R^{2}$ & $0.173 * * *$ & & \\
\hline \multicolumn{4}{|c|}{ Step 5-General Use of Media for Politics } \\
\hline Radio and newspaper & $0.219^{* * *}$ & 0.026 & 0.243 \\
\hline Traditional television & $-0.045^{*}$ & 0.021 & -0.052 \\
\hline$\Delta R^{2}$ & $0.064^{* * *}$ & & \\
\hline \multicolumn{4}{|c|}{ Step 6-Social Media and Streaming TV } \\
\hline SNS political purposes & $0.331^{* * *}$ & 0.034 & 0.381 \\
\hline Streaming television across devices & $0.083^{* * *}$ & 0.016 & 0.125 \\
\hline$\Delta R^{2}$ & $0.054^{* * *}$ & & \\
\hline
\end{tabular}

Altogether, there is thus clear evidence of support for all Hypotheses posed, and it is important to note that even when SNS for political purposes and streaming television were entered as the only two variables in last block in both regression models, the adjusted $R^{2}$ change was significant in both cases. Yet considering these results raises the issue of RQ2, and the extent to which content type interacts with streaming television and relative levels of online and offline political participation.

These factors were thus modeled jointly in factorial ANOVAs with online and offline political participation set again as dependent variables. The streaming of the combined political, apolitical, or both types of content were then set as one independent factor and the hours of streaming television was retained on its hourly scale. Both of these analyses produced statistically significant interactions, $F(6,423)=2.96, p<0.01$, partial $\eta^{2}=0.0410$ for online, and $F(6,423)=2.37, p<0.05$, partial $\eta^{2}=0.033$ for offline political participation. With significant main effects for content type in each model, these results suggest that the type of content is important but even viewing apolitical content-particularly in combination with political content-can relate positively to forms of political participation.

More specifically, the estimated marginal means for online and offline participation levels of those respondents that reported streaming only apolitical versus only political content vary at higher levels of television but actually online declined slightly from 2-3 hours of streaming apolitical content $(\mathrm{M}=0.87, \mathrm{SD}=0.88)$ for online political participation to when hours of streaming television becomes 
more frequent (i.e., for three+ hours; $\mathrm{M}=0.76, \mathrm{SD}=0.96$ ). In all other viewing conditions, for both online and offline political participation, average levels increased for each additional hour of reported streaming. Importantly the greatest effect was observed when respondents indicated binge watching both political and apolitical content more than 3 hours, with the highest means for online $(\mathrm{M}=1.82$, $\mathrm{SD}=1.33)$ and offline $(\mathrm{M}=2.03, \mathrm{SD}=1.17)$ participation.

Results are summarized in Figures 2 and 3, and the closely related patterns signal important similarities between online and offline political participation themselves. Moreover, these analyses also identify how engagement with differing types of streaming television content has largely positive but still differential effects. This finding thus suggests that only more regular streaming of apolitical television may actually be marginally detrimental to participation in politics online at more than 3 hours per day, but on the whole respondents that stream television more are generally participating more, not less, in politics.

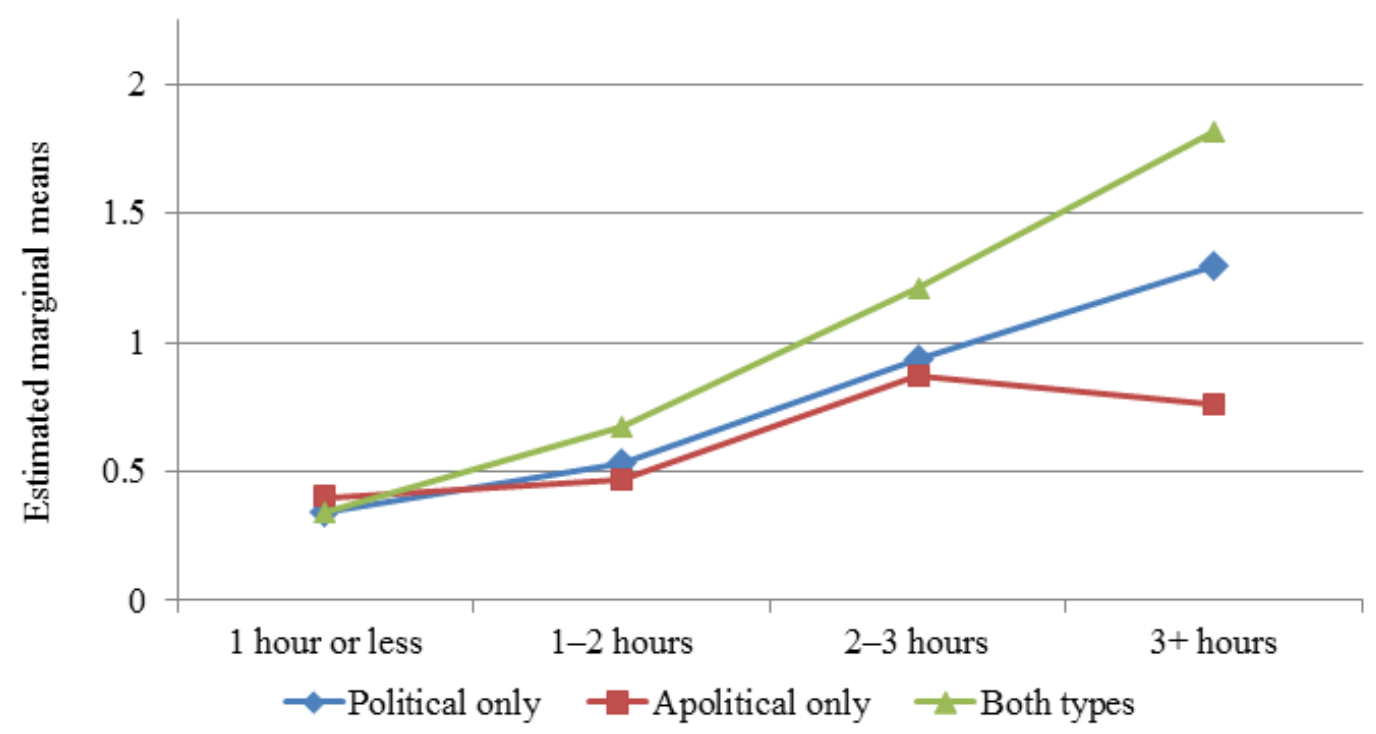

Figure 2. Relationships between types of content binge-watched, frequency of streaming television and online political participation.

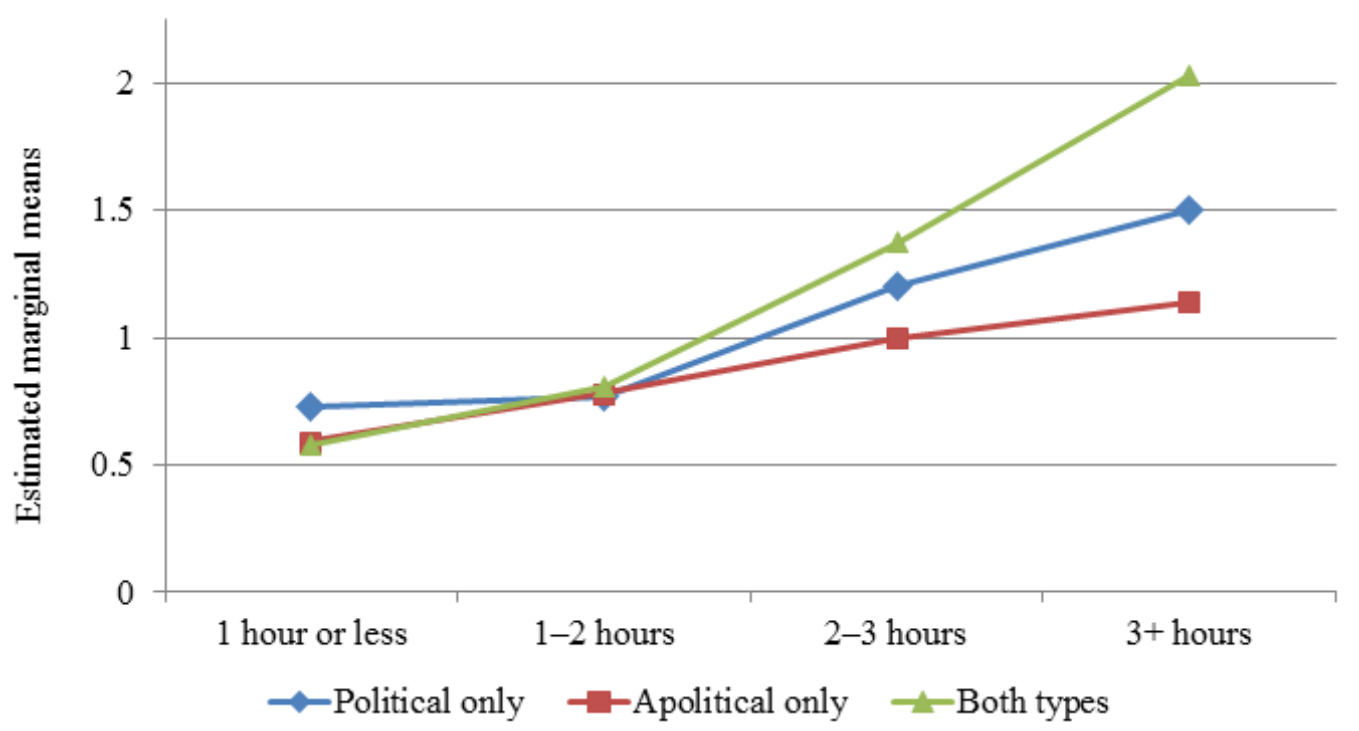

Figure 3. Relationships between types of content binge-watched, frequency of streaming television and offline political participation. 


\section{Discussion and Conclusions}

When taken together, the findings reported here bring together work of Gil de Zuniga et al. [13] on political expression on SNS and the notion of more personalized communication through social media with an entirely emergent phenomenon in streaming television [45] that has yet to be examined for its political import. It does so in such a way that contributes to a body of media system dependency theory $[2,50]$ at the individual level as a reflection of broader social level trends in the United States and the global techno-cultural sphere. These findings also enhance and problematize the existing body of research on television's relationship with political engagement by placing traditional television into conversation with today's increasingly ubiquitous digital landscape where television viewing itself is being transformed as an activity.

Along those lines, this study identifies direct linkages to behavioral aspects of online and offline participation that are related to the increased use SNS and streaming television. Findings also indicate that content engagement with both political and apolitical content, but especially a blend of viewing both, seem to trigger streaming television as useful to both types of political participation at higher levels of viewership. We interpret this as an indication of the number and more importantly the centrality of information functions certain media serve in society [25], as well as the uncertainty avoidance and need for orientation [3] such that these factors are jointly related to increased media dependency in shaping the conditions of increased political participation.

Under the confluence of these conditions in this study, the tendency of this media participation is mostly positive, but (of course) not uniform. When we therefore consider if binge-watching streaming television can really improve politics, we look only to the very recent history of communication research where it was not so long ago that the import of Tweeting and updating Facebook statuses was criticized for its lack of political relevance. Indeed, such content-based critiques been rebuked by the work of Graham and Hajru [51] among others, that have found apolitical content such as reality television often stimulates political talk and engagement. Clearly, the field has come to embrace social media and we argue that streaming television-particularly as an especially personalized communication that shares a logic and sensibility with other social media-represents another dependency oriented pivot point, and reiterate that there are over 138 million subscribers already engaged in this activity worldwide.

Indeed, while the link from now-typical social networking sites such as Facebook and Twitter have regularly been connected, mostly positively, to engagement in politics and participation [6], the vast and growing arena of streaming television has been nearly entirely unexplored, especially for its political implications. While superficially it may be counterintuitive to think that increased frequency of streaming television (i.e., binge-watching, particularly of apolitical content) would be positively related to online, and, even more so, offline political participation, this study not only suggests a significant and positive correlation with streaming television but also explores how watching certain types of programming for political or entertainment purposes can moderate that effect. In terms of interpreting the underlying linkage between streaming television and political participation, we position these findings as extending the earlier work of Graham and Hajru [51], Hoffman and Young [26] and Moy et al. [27], who all found compelling evidence that entertaining media content may activate differing forms of political participation. Indeed, additional scholarship has not only pointed to how preferences for entertainment do not negatively relate to political knowledge and participation [55]), and other work has shown that even apolitical content may also trigger increased interest in politics [56] and serve as a gateway to talk more about politics and also seek more information [57,58].

Still, one of the most notable limitations of this study is its cross-sectional research design that prevents proving causal relationships or empirically establishing directional mechanisms. Future research ought to build more robust panel samples in order to examine the content consumed via streaming television platforms in more detail to better understand whether there are differences among the messaging within the specific programs viewed. From a social learning theory perspective [59], the messaging within media consumed might further intersect with process of consumption to potentially shape political engagement; it is necessary to better understand the content differences 
among platforms in addition to process. Ultimately, this study tracks onto a larger trajectory of the extent to which algorithms in social media in particular, and also personalization in online messaging more generally, shape political exposure, attitudes, and knowledge $[5,9,13]$.

The preliminary evidence here of an emergent phenomenon of streaming television relating positively to political participation offers a number of pathways forward in this arena more broadly, and invites more scholarship into a redefined conceptualization of television viewing that is likely to become not just more common in the future but rather the social and industry norm. Importantly, results from this study suggest that the hundreds of millions of individuals that regularly stream television are also otherwise more engaged in politics. This finding suggests another substantive shift towards more active and connected television viewing [60] that is replete with additional activities to share, comment, post, and interact with others, which may lend television viewing itself towards other forms of participatory activities not only within media but also politics. Put somewhat differently, the findings reported here indicate that it is thus not just what television content users watch but also how they access and engage television content that will be paramount considerations as the field of political communication advances into an era of hybrid media systems [61].

Author Contributions: Both authors mutually agreed on the topic. Jacob Groshek designed the study and survey instrument, and then analyzed the data once collected. Sarah Krongard contributed to the theoretical development of the paper and carrying out the review of literature. Altogether, Jacob Groshek and Sarah Krongard collaboratively wrote the paper, from the Introduction through the Discussion and Conclusions.

Conflicts of Interest: The authors declare no conflict of interest.

\section{References}

1. Groshek, Jacob. “Media, Instability, and Democracy: Examining the Granger-Causal Relationships of 122 Countries from 1946 to 2003." Journal of Communication 61 (2011): 1161-82. [CrossRef]

2. Ball-Rokeach, Sandra J., and Melvin L. DeFleur. "A Dependency Model of Mass-Media Effects." Communication Research 3 (1976): 3-21. [CrossRef]

3. Lee, Eun-Ju, and Soo Youn Oh. "Seek and You Shall Find? How Need for Orientation Moderates Knowledge Gain from Twitter Use." Journal of Communication 63 (2013): 745-65. [CrossRef]

4. Gil de Zúñiga, Homero, Nakwon Jung, and Sebastián Valenzuela. "Social Media Use for News and Individuals' Social Capital, Civic Engagement and Political Participation." Journal of Computer-Mediated Communication 17 (2012): 319-36.

5. Bode, Leticia. "Political News in the News Feed: Learning Politics from Social Media." Mass Communication and Society 19 (2015): 24-48. [CrossRef]

6. Boulianne, Shelley. "Social media use and participation: A meta-analysis of current research." Information, Communication \& Society 18 (2015): 524-38. [CrossRef]

7. Gil de Zúñiga, Homero, Victor Garcia-Perdomo, and Shannon C. McGregor. "What is second screening? Exploring motivations of second screen use and its effect on online political participation." Journal of Communication 65 (2015): 793-815.

8. Vaccari, Cristian, Andrew Chadwick, and Ben O'Loughlin. "Dual Screening the Political: Media Events, Social Media, and Citizen Engagement." Journal of Communication 65 (2015): 1041-61. [CrossRef]

9. Trilling, Damian, and Klaus Schoenbach. "Investigating people's news diets: How online users use offline news." The European Journal of Communication Research 40 (2015): 67-91. [CrossRef]

10. Kulshrestha, Juhi, Muhammad Bilal Zafar, Lisette Espin Noboa, Krishna P. Gummadi, and Saptarshi Ghosh. "Characterizing information diets of social media users." Paper presented at the Ninth International AAAI Conference on Web and Social Media, Oxford University, Oxford, UK, 26-29 May 2015.

11. Bennett, Lance. "The Personalization of Politics: Political Identity, Social Media, and Changing Patterns of Participation." In The Politics of Consumption-The Consumption of Politics. Edited by Dhavan V. Shah, Lewis A. Friedland, Douglas McLeod and Michelle Nelson. Thousand Oaks: Sage Publications, 2012, pp. 20-39. 
12. Bimber, Bruce. "Digital media in the Obama campaigns of 2008 and 2012: Adaptation to the personalized political communication environment." Journal of Information Technology E Politics 11 (2014): 130-50. [CrossRef]

13. Gil de Zúñiga, Homero, Logan Molyneux, and Pei Zheng. "Social media, political expression, and political participation: Panel analysis of lagged and concurrent relationships." Journal of Communication 64 (2014): 612-34.

14. Corporation, Nielsen. "The Total Audience Report: Q1 2016." 2016. Available online: http:/ /www.nielsen.com/content/dam/corporate/us/en/reports-downloads/2016-reports/totalaudience-report-q1-2016.pdf (accessed on 12 September 2016).

15. Lotz, Amanda. The Television Will Be Revolutionized, Kindle ed. New York: NYU Press, 2007.

16. Gaver, William. "Technology affordances." Paper presented at the SIGCHI Conference on Human Factors in Computing Systems, New Orleans, LA, USA, 27 April-2 May 1991.

17. Hilmes, Michele. Only Connect: A Cultural History of Broadcasting in the United States, 4th ed. Boston: Wadsworth, Cengage Learning, 2014.

18. Streeter, Thomas. "Blue skies and strange bedfellows: The discourse of cable television." In The Revolution Wasn't Televised. Edited by Lynn Spigel and Martin Curtin. New York: Routledge, 1997, pp. 221-42.

19. Drew, Dan, and David Weaver. "Voter Learning in the 1988 Presidential Election: Did the Debates and the Media Matter?" Journalism \& Mass Communication Quarterly 68 (1991): 27-37. [CrossRef]

20. Weaver, David, and Dan Drew. "Voter Learning in the 1992 Presidential Election: Did the 'Nontraditional' Media and Debates Matter?" Journalism \& Mass Communication Quarterly 72 (1995): 7-17. [CrossRef]

21. Drew, Dan, and David Weaver. "Voter Learning in the 1996 Presidential Election: Did the Media Matter?" Journalism \& Mass Communication Quarterly 75 (1998): 292-301.

22. Weaver, David, and Dan Drew. "Voter Learning and Interest in the 2000 Presidential Election: Did the Media Matter?" Journalism \& Mass Communication Quarterly 78 (2001): 787-98. [CrossRef]

23. Drew, Dan, and David Weaver. "Voter Learning in the 2004 Presidential Election: Did the Media Matter?" Journalism \& Mass Communication Quarterly 83 (2006): 25-42.

24. Bucy, Erik, and Jacob Groshek. "Empirical Support for the Media Participation Hypothesis: Longitudinal Trends across Presidential Elections, 1992-2012." Paper presented at American Association for Public Opinion Research (AAPOR) 69th Annual Conference, Anaheim, CA, USA, 15-18 May 2014.

25. Groshek, Jacob, and Daniela Dimitrova. "A Cross-Section of Political Involvement, Partisanship and Online Media in Middle America during the 2008 Presidential Campaign." Atlantic Journal of Communication 21 (2013): 108-24. [CrossRef]

26. Hoffman, Lindsay H., and Dannagal G. Young. "Satire, punch lines, and the nightly news: Untangling media effects on political participation." Communication Research Reports 28 (2011): 159-68. [CrossRef]

27. Moy, Patricia, Michael A. Xenos, and Verena K. Hess. "Communication and citizenship: Mapping the political effects of infotainment." Mass Communication \& Society 8 (2005): 111-31. [CrossRef]

28. McLeod, Jack M., Carroll J. Glynn, and Daniel G. McDonald. "Issues and images: The influence of media reliance in voting decisions." Communication Research 10 (1983): 37-58. [CrossRef]

29. Putnam, Robert D. “Bowling alone: America's declining social capital." Journal of Democracy 6 (1995): 65-78. [CrossRef]

30. Putnam, Robert D. Bowling Alone: The Collapse and Revival of American Community. New York: Simon and Schuster, 2001.

31. Uslaner, Eric M. "Social capital, television, and the 'mean world': Trust, optimism, and civic participation." Political Psychology 19 (1998): 441-67. [CrossRef]

32. Moy, Patricia, Dietram A. Scheufele, and R. Lance Holbert. “Television use and social capital: Testing Putnam's time displacement hypothesis." Mass Communication and Society 2 (1999): 27-45. [CrossRef]

33. Shah, Dhavan V. "Civic Engagement, Interpersonal Trust, and Television Use: An Individual-Level Assessment of Social Capital." Political Psychology 19 (1998): 469-96. [CrossRef]

34. Mutz, Diana C., and Lilach Nir. "Not necessarily the news: Does fictional television influence real-world policy preferences?" Mass Communication and Society 13 (2010): 196-217. [CrossRef]

35. Street, John, Sanna Inthorn, and Martin Scott. "Playing at politics? Popular culture as political engagement." Parliamentary Affairs 65 (2012): 338-58. [CrossRef] 
36. Mander, Jason. "Digital versus Traditional Media Consumption. London: GlobalWebIndex." 2015. Available online: http:/ /insight.globalwebindex.net/hs-fs/hub/304927/file-1414878665pdf/Reports/GWI_Media_ Consumption_Summary_Q3_2014.pdf (accessed on 15 June 2016).

37. Weber, Harrison, and Jordan Novet. "Netflix now has more than 75 million subscribers." Venture Beat, 19 January 2016. Available online: http:/ /venturebeat.com/2016/01/19/netflix-now-has-more-than-75million-subscribers/ (accessed on 13 June 2016).

38. McAlone, Nathan. "People became even more addicted to Netflix in 2015, according to Goldman Sachs." Business Insider, 11 January 2016. Available online: http:/ / uk.businessinsider.com/subscribers-spent-moretime-per-person-watching-netflix-in-2015-2016-1?utm_source=feedly\&utm_medium=webfeeds?r=US\& $\mathrm{IR}=\mathrm{T}$ (accessed on 15 June 2016).

39. The Hulu Blog. "The Hulu Drumbeat Continues at the 2015 Upfront Presentation." Available online: http:/ /blog.hulu.com/2015/04/29/2015-hulu-upfront-presentation/ (accessed on 20 February 2016).

40. Kline, Daniel B. "How Many Prime Members Does Amazon Have (And Why It Matters)." The Motley Fool, 26 January 2016. Available online: http:/ /www.fool.com/investing/general/2016/01/26/how-many-primemembers-does-amazon-have-and-why-it.aspx (accessed on 15 June 2016).

41. The Nielsen Company. "Nielsen Comparable Metrics Q3 2015." 2016. Available online: http:/ /www.nielsen.com/content/dam/corporate/us/en/reports-downloads/2016-reports / comparable-metrics-report-q3-2015.pdf (accessed on 16 June 2016).

42. Alvarez-Monzoncillo, Jose Maria. Watching the Internet: The Future of TV? Kindle ed. Porto: Media XXI, 2015.

43. Guardian. "BBC considering scrapping channel-based structure in radical shakeup." 15 Feburary 2016. Available online: http:/ /www.theguardian.com/media/2016/feb/15/bbc-considering-scrapping-channelbased-structure-radical-shakeup (accessed on 16 June 2016).

44. Napoli, Philip M. Audience Evolution. New York: Columbia University Press, 2010.

45. Hallinan, Blake, and Ted Striphas. "Recommended for you: The Netflix Prize and the production of algorithmic culture." New Media \& Society 18 (2014): 117-37. [CrossRef]

46. Cheney-Lippold, John. "A New Algorithmic Identity: Soft Biopolitics and the Modulation of Control." Theory, Culture E Society 28 (2011): 164-81.

47. José, Van Dijck, and Thomas Poell. “Understanding social media logic.” Media and Communication 1 (2013): 2-14.

48. Miller, M. Mark, and Stephen D. Reese. "Media Dependency as Interaction: Effects of Exposure and Reliance on Political Activity and Efficacy." Communication Research 9 (1982): 227-48. [CrossRef]

49. McLeod, Jack M., and Daniel G. McDonald. "Beyond simple exposure media orientations and their impact on political processes." Communication Research 12 (1985): 3-33. [CrossRef]

50. Rubin, Alan M., and Sven Windahl. "The uses and dependency model of mass communication." Critical Studies in Media Communication 3 (1986): 184-99. [CrossRef]

51. Graham, Todd, and Auli Hajru. "Reality TV as a trigger of everyday political talk in the net-based public sphere." European Journal of Communication 26 (2011): 18-32. [CrossRef]

52. Moy, Patricia, Michael A. Xenos, and Verena K. Hess. "Priming effects of late-night comedy." International Journal of Public Opinion Research 18 (2006): 198-210. [CrossRef]

53. Baker, Reg, Stephen J. Blumberg, J. Michael Brick, Mick P. Couper, Melanie Courtright, J. Michael Dennis, Don Dillman, Martin R. Frankel, Philip Garland, and Robert M. Groves. “AAPOR Report on Online Panels.” 2010. Available online: https://pprg.stanford.edu/wp-content/uploads/2010-AAPOR-Report-on-OnlinePanels.pdf (accessed on 12 June 2016.).

54. Peifer, Jason, and Kelly Garrett. "Best practices for working with opt-in online panels." 2014. Available online: http:/ / www.comm.ohio-state.edu/Opt-in_panel_best_practices.pdf (accessed on 14 June 2016).

55. De Vreese, Claes H., and Hajo Boomgaarden. "News, Political Knowledge and Participation: The Differential Effects of News Media Exposure on Political Knowledge and Participation." Acta Politica 41 (2006): 317-41. [CrossRef]

56. Lee, Hoon, and Nojin Kwak. “The Affect Effect of Political Satire: Sarcastic Humor, Negative Emotions, and Political Participation." Mass Communication and Society 17 (2014): 307-28. [CrossRef]

57. Graham, Todd. "Needles in a Haystack: A New Approach for Identifying and Assessing Political Talk in Nonpolitical Discussion Forums." Javnost-The Public 15 (2008): 17-36. [CrossRef] 
58. Hollander, Barry A. “Late-Night Learning: Do Entertainment Programs Increase Political Campaign Knowledge for Young Viewers?" Journal of Broadcasting E Electronic Media 49 (2010): 402-15. [CrossRef]

59. Bandura, Albert. Social Learning Theory. New York: General Learning Press, 1977.

60. Lin, Jhih-Syuan, Yongjun Sung, and Kuan-Ju Chen. "Social television: Examining the antecedents and consequences of connected TV viewing." Computers in Human Behavior 58 (2016): 171-78. [CrossRef]

61. Chadwick, Andrew. The Hybrid Media System: Politics and Power. New York: Oxford University Press, 2013.

(C) 2016 by the authors; licensee MDPI, Basel, Switzerland. This article is an open access article distributed under the terms and conditions of the Creative Commons Attribution (CC-BY) license (http://creativecommons.org/licenses/by/4.0/). 